\title{
Modelling Sulfonation Kinetics On The Sodium Lignosulphonate Synthesis From Black Liquor
}

\author{
Hapsoro Aruno Aji ${ }^{1}$, Bambang Pramudono ${ }^{2, *}$, Slamet Priyanto ${ }^{3}$ \\ ${ }^{1}$ Master Degree of Department of Chemical Engineering, Faculty of Engineering, Diponegoro University, Jl. Prof. Sudarto, Tembalang- \\ Semarang, 50275, Telp/fax: (024)7460058 / (024)76480675 \\ ${ }^{2}$ Department of Chemical Engineering, Faculty of Engineering, Diponegoro University „Jl. Prof. Sudarto, Tembalang-Semarang, 50275, \\ Telp/fax: (024)7460058 / (024)76480675 \\ ${ }^{3}$ Doctor Degree of Department of Chemical Engineering, Faculty of Engineering, Diponegoro University, Jl. Prof. Sudarto, Tembalang- \\ Semarang, 50275, Telp/fax: (024)7460058 / (024)76480675
}

\begin{abstract}
Surfactant is a compound that has the ability to lower the interfacial tension between the face of two phases (liquid). The need of surfactant has increased along with the development of the industrial sector. One example is sodium lignosulfonat (SLS) which is useful to improve oil acquisition in its application for EOR (Enhanced Oil Recovery). SLS is a result of the reaction between lignin, $\mathrm{NaHSO}_{3}$ (bisulfite) and sodium hydroxide as catalyst. The purpose of this research is to determining the reaction mechanism and determining the value of the reaction rate constant $(\mathrm{k})$. The sulphonation kinetics of lignin was carried out in various temperature $\left(50,60,70,80\right.$, and $\left.90^{\circ} \mathrm{C}\right)$. From this research obtained a positive (linear) response between sulfonation temperature against reaction rate constants. The lowest $\mathrm{k}$ values obtained $\mathrm{k}_{50}=2,05 \mathrm{x}$ $10^{-4}$ minute $^{-1}$ and the highest one is $\mathrm{k}_{90}=3,35 \times 10^{-4}$. From graphycally calculation obtained the value of $\mathrm{A}$ is 0,015 and the energy activation $(\mathrm{Ea})$ is $-11,708 \mathrm{~kJ} / \mathrm{mol}$ with $\mathrm{R}^{2}=95,69 \%$. The correlation of the temperature influence to the constant of reaction rate espressed in arhenius equation as follows :
\end{abstract}

$$
\mathrm{k}=0,015 \exp ^{(-1408,3 / \mathrm{T})}
$$

\section{Introduction}

Black liquor (BL) is side result of pulp processing with lignin as main component approximately $46 \%$ of total solid [1]. In successive year, Black liquor production increase as the growth of paper demand. This solution is stable, complex, smelly and has toxic compound such hidrogen sulfide, methyl mercaptan. It means, dumping to the environment cause pollution. Nowadays, the utilization of BL only for energy source for pulp mill, and use as biofuel[2]. Black liquor has high of density is caused by black liquor also has high of solid content[3].

Lignin is a major wood component beside cellulose and hemicellulose, consists of three dimensional monomer namely p-coumaryl alcohol $(\mathrm{H})$, koniferil alcohol (G) and sinapyl alcohol (S)[4]. Lignin are formed by polymerization of monomers which differ structure depending on plant type. It means that, each plant type have different structure of lignin[5]. Lignin is colorless, amorphorus, renewable[6]. Usually, lignin is used as a cement water reducer, composite materials [7], surfactant and dispersant for cement admixture [8], Flocculants for waste water[9]. Basicly lignin is hydrophobic in nature, so lignin insoluble in water, acid, and hydrocarbon but soluble in alkali solution. It means, lignin from BL can be isolate by acid.
Surfactant are compound that lower the interfacial tension, between two liquids. It compose of polar (hydrophilic) and non polar (lypophilic). The need of surfactant in Indonesia increase a long with the development in the industrial sector. During this time, surfactant commonly used is petroleum-based. This surfactant have good performance, but not ecofriendly, hard to degrade, comes from non-renewable materials[10]. Therefore, it takes an effort to create a new surfactant with the same good or better performance and more sustainable. Development of surfactants is being carried out which one of them is sodium lignosulfonat (SLS) from biomass such as lignin. SLS can be produced from lignin through a sulfonation process. This process aim to substitute hydroxyl groups with sulphonate groups which is more polar (Fig.1). The use of this surfactant such as emulsifying agents, emulsion stabilizer, dye dispersant, floacculants[11], for mud viscosity control during deep oil well drilling, corrosion inhibitor [13].

This research is intended to study the kinetic reaction of sulfonation process in batch reactor. It becomes important to determine the chemical reaction mechanism and determine the value of reaction rate constant $(\mathrm{k})$. The reaction rate is defined as increasing

Corresponding author: pramudono2004@yahoo.com 
the amount of product or decreasing the amount of reactant. Sodium lignosulphonate can be reduced by sulfonation process following reaction :

Lignin + Natrium bisulfate $\rightarrow$ SLS + water

\section{Experimental Method}

\subsection{Materials}

Black liquor obtained from PT. Indah kiat pulp and paper (Riau), lignin isolate, commercial lignin from sigma, sodium bisulfit $(\sim 40 \% \mathrm{v} / \mathrm{v}$ solution in water $)$ from sigma, sulfuric acid 98\% from PT. Indrasari, natrium hydroxide $(\mathrm{NaOH}) 98 \%$ from merck, methanol $99,8 \% \mathrm{v} / \mathrm{v}$ from PT. Indrasari, aquadest, and aquabidest.

\subsection{Synthesis of surfactant}

2 grams of lignin isolate reacted with $1,77 \mathrm{ml}$ of $40 \%$ $\mathrm{v} / \mathrm{v}$ sodium bisulfit $\left(\mathrm{NaHSO}_{3}\right)$ in $60 \mathrm{ml}$ aquades. From previous research, obtained that the best of sulfonation condition in ratio (lignin: $\mathrm{NaHSO}_{3}$ ) is 1 gram of lignin reacted with 0,458 gram $\mathrm{NaHSO}_{3}$, initial $\mathrm{pH} \mathrm{8,31} \mathrm{and}$ $79,67^{\circ} \mathrm{C}$ in temp. Sulfonation temp (T) for reaction kinetic studies is $50,60,70,80$, and $90^{\circ} \mathrm{C}$. Every 20 $\min (\mathrm{t})$, samples are taken to analyze.

\subsection{Kinetic Reaction}

Experiment performed in batch reactor with fix volume, and temperature condition. Follow as $2^{\text {nd }}$ order reaction.

$$
[\text { in }]-[\text { out }]+[\text { rate of rx }]=[\text { acc }]
$$

Batch reactor, so $\mathrm{V}=$ constant

$$
0-0-\mathrm{C} . \mathrm{V} . \mathrm{k}=\mathrm{dVC} / \mathrm{dt}
$$

If conversion of $\mathrm{A}=\mathrm{Xa}$, and initial concentration of $\mathrm{A}$ and $\mathrm{B}$ symbolized as $\mathrm{Ca}_{0}, \mathrm{Cb}_{0}$ so we get

$$
-x_{\mathbb{L}}=k_{\cdot} C_{A 0}\left(1-X_{A}\right)\left(C_{B D}-C_{A 0} \cdot X_{A}\right)
$$

If $\mathrm{C}_{\mathrm{b} 0}=\mathrm{M} \cdot \mathrm{C}_{\mathrm{a} 0}$, so $\mathrm{M}=\mathrm{C}_{\mathrm{b} 0} / \mathrm{C}_{\mathrm{a} 0}$ and we get

$$
\begin{aligned}
& -r_{G}=k \cdot C_{A}^{2}\left(1-X_{A}\right)\left(M-X_{A}\right) \\
& \ln \frac{M-X_{A D}}{M \mathbb{M}-X_{A D}}=\ln \frac{C_{A D} C_{B}}{C_{B D} C_{A D}} \\
& \ln \frac{C_{B}}{C_{A D}}=\left(C_{B D}-C_{A D}\right) \cdot k \cdot t+\ln M
\end{aligned}
$$

\subsection{Analysis}

UV spectrophotometric method is the best suited for determining the concentration of component like lignin, sodium bisulfit, and sodium lignosulfonat (SLS). In this experiment concentration were analyze by UV mini - 1240 spectrophotometer pharco - 300. Each component have different wavelength, for lignin $\lambda=205 \mathrm{~nm}^{[14]}$, for sodium bisulit $\lambda=288 \mathrm{~nm}$, and for Sodium lignosulfonat $\lambda=232 \mathrm{~nm}[15]$.

\section{Result And Discussion}

\subsection{Reactant concentration vs Temperature}

From fig.1 and fig.2, known that at reactant concentration per unit time $(\mathrm{t})$ decrease. It means that, at the longer time more reactants are converted as surfactant. The lowest concentration occurs at $90^{\circ} \mathrm{C}$, it is indicate that at the temperature (T) give the best condition in yield of surfactant.

a.

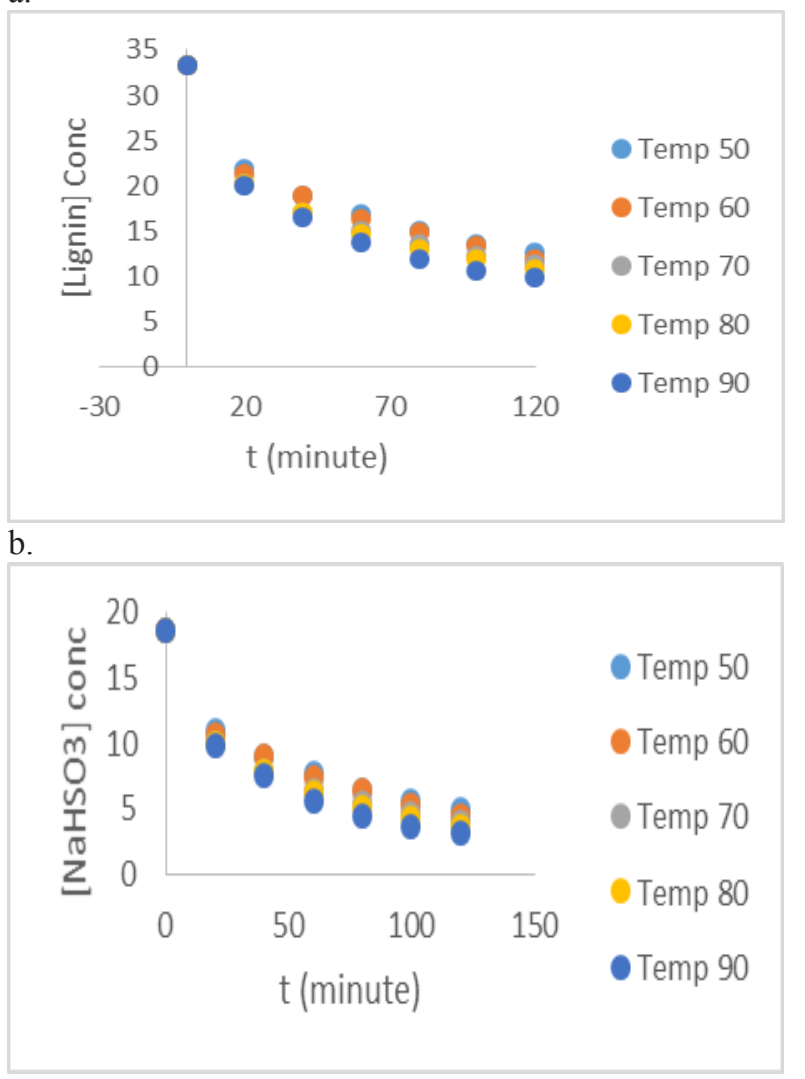

Fig. 1. Reactant concentration (a) Lignin and (b) Sodium bisulfit.

\subsection{Reaction rate constant (k) vs Temperature}

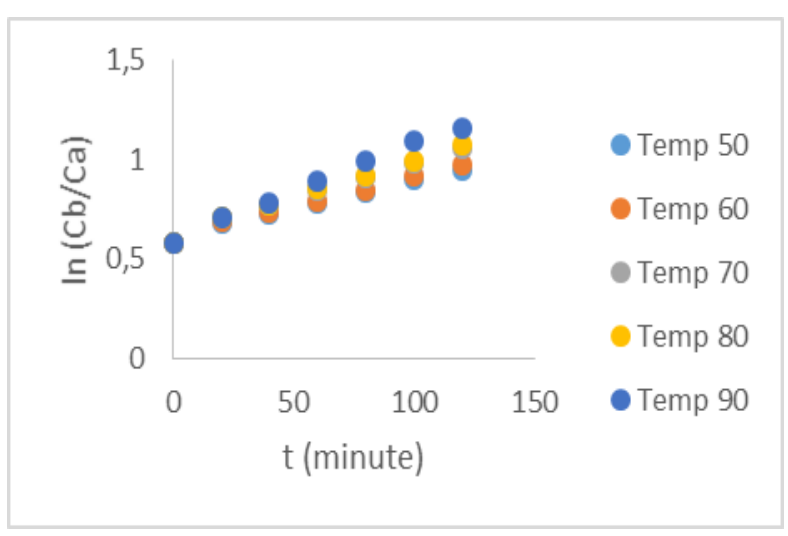

Fig. $2 . \ln (\mathrm{Cb} / \mathrm{Ca})$ vs time $(\mathrm{t})$ 
Table 1. Reaction rate constant vs $\mathrm{T}$

\begin{tabular}{ccc}
\hline Suhu $\left({ }^{\mathbf{0}} \mathbf{C}\right)$ & $\mathbf{l n} \mathbf{C}_{\mathbf{B} \mathbf{0}}-\mathbf{C}_{\mathbf{A} \mathbf{0}}(\mathbf{k})$ & $\mathbf{k}$ \\
\hline 50 & 0,0030 & $2,05 \times 10^{-4}$ \\
60 & 0,0032 & $2,19 \times 10^{-4}$ \\
70 & 0,0038 & $2,60 \times 10^{-4}$ \\
80 & 0,0040 & $2,74 \times 10^{-4}$ \\
90 & 0,0049 & $3,35 \times 10^{-4}$ \\
\hline
\end{tabular}

Based on fig. 2 and table 1 known that at the higher temperature of sulfonation process, reaction rate constant also higher. This is due to at the higher temperature $(\mathrm{T})$, the reactant molecular activation and the collision factor also increase. The reaction rate constant were increase at 1,1 fold every $10 \mathrm{oC}$ increment. based on the "rule of thumb" which states that every 10 degree temperature rise, the reaction rate constant (k) will increase twice as much. But in this study, only 1.1 times increased. It's cause the sulfonation reaction rate is affected by the concentration of the lignin active site and the total SO2 ion concentration. This result corresponds to the arrhenius equation, that temperature is proportional to the reaction rate constant $(\mathrm{k})$.

\subsection{Determine A and Ea}

Ea (activation energy) is the minimum energy required for the reaction occur. Activation energy determined using Arrhenius equation.

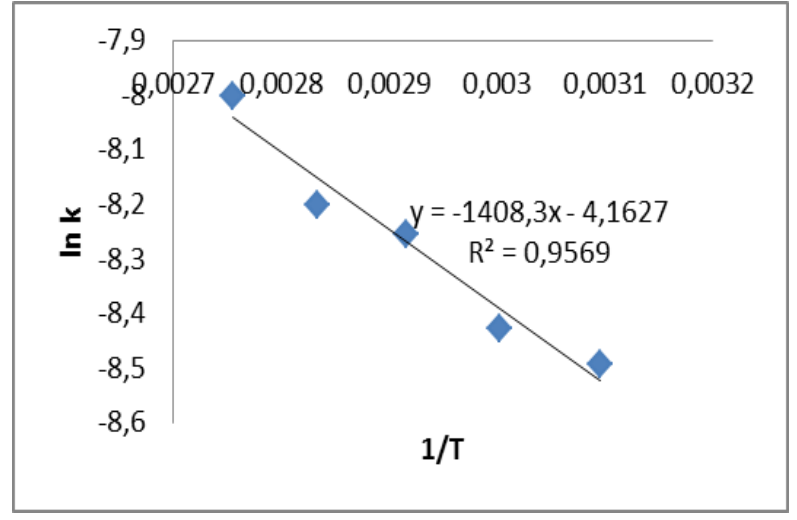

Fig. 3. $\ln \mathrm{k}$ vs $1 / \mathrm{T}$

Based on fig.3, show that slope representing the value of $-\mathrm{Ea} / \mathrm{R}$ and the intercept representing $\ln \mathrm{A}$. From the calculation, value of $-\mathrm{Ea}$ (with $\mathrm{R}=8,314$ $\mathrm{J} / \mathrm{K} \cdot \mathrm{mol}$ ) is $11,708 \mathrm{~kJ} / \mathrm{mol}$ and the collision factor 0,015 . The results showed that the value of Ea in this study was smaller when compared to the ismiyati (2013) in which Ea obtained was $21.27 \mathrm{~kJ} / \mathrm{mol}$. It is indicates that the energy required for sulfonation reaction is smaller. For this data experiment, reaction rate constant follow this equation :

$$
\mathrm{k}=0,0015 \cdot \mathrm{e}^{-1408,3 / \mathrm{T}}
$$

\subsection{Validation of reaction kinetics model}

Reaction kinetics model used for the calculation of reactor capacity, in order to scale up the capacity of production. The best condition of sulfonation process is $90^{\circ} \mathrm{C}$ in temperature, with reaction rate constant $3,35 \times 10^{-4}$. Validation process is performed by comparing the value of $\mathrm{Ca}_{1 a b} 90 \mathrm{oC}$ and $\mathrm{Ca}_{\text {calc } 90 \mathrm{C}}$.

$$
\begin{aligned}
& \ln (\mathrm{Cb} / \mathrm{Ca})=\left(\mathrm{Cb}_{0}-\mathrm{Ca}_{0}\right) \mathrm{k} . \mathrm{t}+\ln \mathrm{M} \\
& \mathrm{Ca}=\mathrm{Cb} / \mathrm{M} \cdot \mathrm{e}^{(\mathrm{Ca} 0-\mathrm{Cb} 0) \cdot \mathrm{k}}
\end{aligned}
$$

Table 2. Validation of Ca Calculation (at $90^{\circ} \mathrm{C}$ )

\begin{tabular}{ccc}
\hline Time (minutes) & Ca lab & Ca calc \\
\hline 0 & 33,33 & 33,9603 \\
20 & 19,95 & 19,6089 \\
40 & 16,58 & 16,6623 \\
60 & 13,63 & 13,5826 \\
80 & 11,86 & 11,8131 \\
100 & 10,59 & 10,5123 \\
120 & 9,92 & 10,1249 \\
\hline
\end{tabular}

Based on the data, it can be concluded that reaction kinetics model is acceptable. From the calculation, the average of \%error kinetics model is $1,091 \%$.

\section{Conclusion}

Lignin sulfonation reaction kinetics follow as $2^{\text {nd }}$ order with the highest reaction rate constant occur at $90^{\circ} \mathrm{C}$, with $\mathrm{k}=3,35 \times 10^{-4}$ and give 1,1 fold every $10^{\circ} \mathrm{C}$ increment. The activation energy, collision factor (A) is $11,708 \mathrm{~kJ} / \mathrm{mol}$ and 0,0015 . Validation indicate that laboratory data $\left(\mathrm{Ca}_{\text {lab }}\right)$ and calculation $\left(\mathrm{Ca}_{\text {calc }}\right)$ result in similarity, so the reaction kinetics model is acceptable.

\section{References}

1. Sjöström, E. Wood chemistry fundamentals and application (2nd edition) (CA:Academic Press, Inc., San Diego, 1993)

2. Bora, M.K., J. Engineering Science and Tehnology: an International Journal 4, 2 (2014)

3. Alabi, S.B., Development and implementation of an online kraft black liquor viscosity soft sensor. (Christchurch, New Zealand, 2010)

4. Fasching, M., Schroder, P., Wollboldt, R.P., Webber, H.K., Sixta, H., Holzforschung 62, 15-23 (2008)

5. Norgren, M., Edlund, H., Current opinion in colloid and interface science 19, 5, 409-416 (2014)

6. Radoykova, T., Nenkova, S., Valchev, I., Journal of chemical technology and metallurgy 48, 5, 524529 (2013)

7. Kamoun, A., Jelidi, A., Chaabouni, M., Cement and Concrete research 33, 995-1003 (2003)

8. Kumar, M.N.S., Monhanty, A.K., Erickson, L., Misra, M., J. Bio. Mater. Bioenergy 4, 1-24 (2009) 
9. Ouyang, X., Ke, L., Qiu, X., Guo, Y., Pang, Y., J. Dispersion Sci. Techol, 30, 1, 1-6 (2009)

10. Wei, Y., Cheng, F., Zheng, H., Carbohydr Polym, 74, 673-679 (2008)

11. Afif, M.F., Optimizing composition of Sodium lignosulfonate and Oleic acid to reach IFT 10-3 Mixed surfactant on EOR operation. (In Indonesia Petroleum Association, 2015)

12. John Wiley \& Sons, Inc http://www.scribd.com/doc/30137763/Lignin

(Accessed on 10 November 2017)

13. Altwaiq, A., Abdel-Raheem, R., Alshamaileh, E., Al-luaibi, S., Khouri, S., Eurasian J of Anal Chem 10, 1, (2015)

14. Jahan, M.S., Mun, S.P., J. Of wood chemistry and technology 272 (2007)

15. Wesco Technologies. Typical properties of weschem ammonium lignosulfonat, calcium lignosulfonate, sodium lignosulfonate, zinc lignosulfonate, CA.92674 - 3880 (USA, 1995) 